\title{
Uma análise do
}

acesso à educação no

Brasil por jovens

de 18 a 24 anos

no período

de 1995 a 2006

CIBELE YAHN DE

ANDRADE e

NORBERTO DACHS

são pesquisadores do

Núcleo de Estudos de

Políticas Públicas (NEPP)

da Unicamp. 


\section{INTRODUÇÃO}

A intensificação do conhecimento como insumo para o desenvolvimento econômico destacou nas agendas nacionais a questão do acesso ao ensino superior. Nos países mais desenvolvidos tal acesso cresceu intensamente nos trinta anos compreendidos entre 1965 e 1995, como mostra a Figura 1, com um crescimento menos intenso de 1995 a 2006.

FIGURA 1

Porcentagem de jovens com acesso ao ensino superior em 1965, 1995 e em 2006

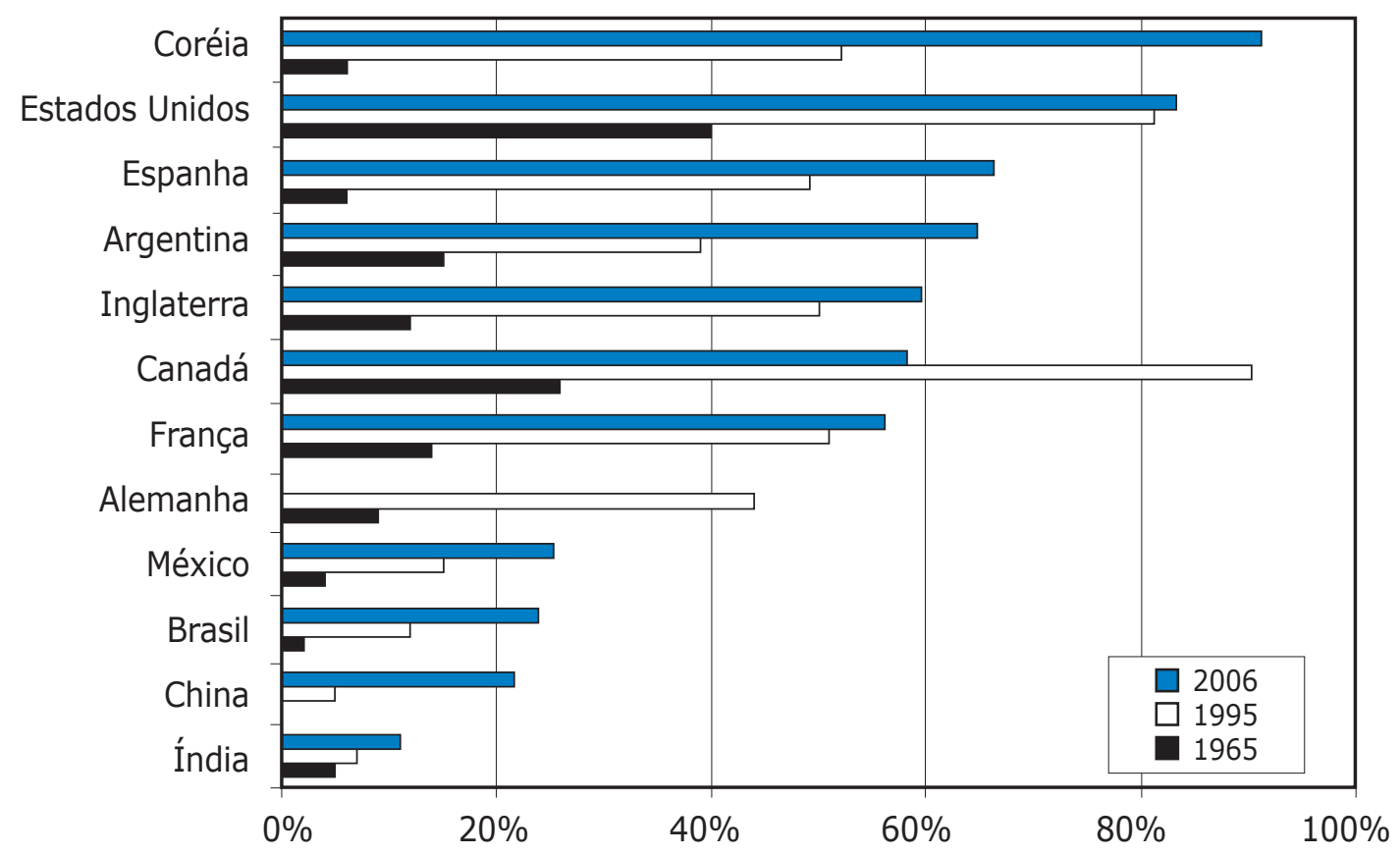

Matrículas em relação à população de jovens de 18 a 24 anos

0 Brasil apresentou um atraso bastante significativo em relação aos investimentos na educação. 0 reflexo disso pode ser percebido desde o final do século XIX, quando muitos países já tinham universalizado o 
acesso à educação fundamental. Esse desnível foi se acentuando com o passar dos anos, mostrando uma defasagem significativa afetando consequientemente o acesso ao ensino superior no Brasil.

Neste trabalho analisamos a evolução do acesso à educação no Brasil no período de 1995 a 2006, por jovens com idade entre 18 e 24 anos. Para melhor compreensão das restrições ao acesso ao ensino superior, que seria o nível compatível com essa faixa de idade, é necessário analisar a transição desses jovens nos ensinos fundamental e médio e as características da oferta do sistema de ensino superior.

\section{DADOS E METODOLOGIA}

\section{Fonte dos dados e classificação dos níveis de escolaridade}

Para o levantamento dos dados para o ensino superior considerou-se a população com idade compreendida entre 18 e 24 anos, consistentemente com as estatísticas internacionais, o que permite a comparabilidade das informações levantadas.

As informações apresentadas originaram-se da série das Pesquisas Nacionais por Amostra de Domicílios (PNADs) do Instituto Brasileiro de Geografia e Estatística (IBGE) referentes aos anos de 1995 a 2006 .

As categorias estabelecidas para a classificação da situação de escolaridade da população com idade entre 18 e 24 anos são mostradas na Tabela 1 .

Em relação às informações sobre as redes de ensino superior, pública ou privada, levamos em conta apenas os que se encontravam matriculados em cursos de graduação na ocasião da aplicação dos questionários da PNAD/IBGE, uma vez que os questionários aplicados não obtêm a informação sobre a esfera administrativa da instituição em que os informantes estudaram anteriormente. Dessa forma, os dados sobre os matriculados no ensino superior público e privado não contemplam a informação se esses jovens concluíram ou não o curso que frequientavam quando prestaram as informações ao IBGE. Por isso os qualificamos, para a finalidade deste trabalho, como parcela da população que teve acesso ao ensino superior. Outra consideração é que a PNAD introduz somente a partir de 2003 a informação sobre a rede de ensino ser pública ou privada.

\section{Distribuição de rendimentos da população e classificação da cor autodeclarada}

Ainformação sobre raça/cor pesquisada pelo IBGE é baseada em autodeclaração do informante, tendo como referência a cor da pele, de acordo com as seguintes alternativas apresentadas previamente: "branco", "preto", "pardo" e "amarelo", além da categoria "indígena"

Para a finalidade deste estudo, agregamos a população em apenas dois grupos: "brancos" e "não-brancos". O grupo dos "não-brancos" é constituído pelas pessoas que se autodeclararam como pardos (42\% do total da população) somados aos negros (6\%) e aos índios $(0,2 \%)$. Vale destacar que, nos quesitos levantados pelo presente trabalho, os negros e os pardos apresentam condições de escolaridade muito semelhantes. O grupo dos brancos é composto pelas pessoas que se autodeclararam como brancas (52\% do total da população) somadas às que se autodeclararam como amarelas $(0,4)$. O grupo dos amarelos, apesar de ser proporcionalmente pequeno e, por conseguinte, não alterar os resultados do grupo dos brancos, apresenta condições de escolaridade superiores em todos os quesitos levantados nesta pesquisa.

Para a classificação de rendimentos da população analisada foi utilizada a divisão em quintis da renda familiar per capita, ou 
TABELA 1

Classificação da situação de escolaridade da população com idade entre 18 e 24 anos

\begin{tabular}{|c|c|}
\hline $\begin{array}{c}\text { Classificação da situação de } \\
\text { escolaridade }\end{array}$ & $\begin{array}{c}\text { Situação de escolaridade apresentada } \\
\text { nas PNADs }\end{array}$ \\
\hline Não concluiu o ensino fundamental & $\begin{array}{l}\text { Nunca freqüentou a escola } \\
\text { Evadiu sem concluir o ensino fundamental } \\
\text { Cursa o supletivo de ensino fundamental } \\
\text { Cursa o regular do ensino fundamental } \\
\text { Cursa alfabetização de adultos }\end{array}$ \\
\hline $\begin{array}{l}\text { Concluiu apenas o ensino } \\
\text { fundamental }\end{array}$ & $\begin{array}{l}\text { Não freqüenta, mas concluiu ensino fundamental } \\
\text { Evadiu sem concluir o ensino médio } \\
\text { Cursa o supletivo do ensino médio } \\
\text { Cursa o regular do ensino médio }\end{array}$ \\
\hline $\begin{array}{l}\text { Concluiu o ensino médio } \\
\text { "Qualificado para o ensino superior" }\end{array}$ & $\begin{array}{l}\text { Freqüenta curso pré-vestibular } \\
\text { Não freqüenta atualmente, mas concluiu o ensino médio }\end{array}$ \\
\hline $\begin{array}{l}\text { Teve acesso ao ensino superior } \\
\text { (Freqüenta ou não) }\end{array}$ & $\begin{array}{l}\text { Freqüenta o ensino superior } \\
\text { Evadiu sem concluir o superior } \\
\text { Freqüenta a pós-graduação } \\
\text { Freqüentou a pós-graduação }\end{array}$ \\
\hline
\end{tabular}

seja, a razão entre a soma das rendas de todos os membros do domicílio e o número de membros desse domicílio. Considerase ainda que a PNAD introduz, somente a partir de 2003, a informação sobre as categorias pública e privada em relação às redes de ensino.

\section{CARACTERISTICAS DA OFERTA DO ENSINO SUPERIOR}

Na década de 70, paralelamente a um crescimento limitado do setor público, há um primeiro ciclo de expansão ocorrido no âmbito do ensino privado. Tal crescimento introduziu uma diferenciação e hierarquiza- ção entre os estabelecimentos. Às antigas universidades privadas de natureza confessional ou não-lucrativa, somaram-se, em maior número, as instituições criadas pela iniciativa empresarial. Passam a predominar pequenas instituições isoladas dedicadas exclusivamente ao ensino para atendimento da demanda e cujos padrões de qualidade se constituíram de modo bastante heterogêneo. Assiste-se também, a partir da década de 80, apesar da desaceleração do crescimento nesse período, à transformação de instituições isoladas em universidades, até então prerrogativa limitada às instituições públicas e algumas de natureza confessional.

Nos anos 90 a expansão do ensino superior foi intensa e ancorada, fundamentalmente, no setor privado. Em ritmo menor, cresce também a oferta pública (Fapesp, 2001)².
2 Parte dos dados apresentados neste artigo originaram-se do trabalho de pesquisa para a publicação: "Indicadores de Ciência, Tecnologia e Inovação em São Paulo-Fapesp". Porém, a análise aqui apresentada éde inteira responsabilidade dos autores deste artigo. 
Em conseqüência, a participação do segmento particular passou de $62 \%$ para $70 \%$, no Brasil. Ritmo intenso de crescimento, tanto em termos absolutos como relativos. O setor público, por sua vez, apresentou queda significativa em sua participação. As instituições federais e estaduais - responsáveis pela oferta do ensino gratuito - apresentaram queda proporcional em relação ao crescimento do setor privado de $32 \%$ para $27 \%$ das matrículas no Brasil. nas demais regiões do país, embora com intensidades e patamares diferentes. $\mathrm{Na}$ Região Sudeste, excluindo-se o estado de São Paulo, as matrículas no setor privado passam de $64 \%$, em 1995 , para $81 \%$, em 2006; na Região Sul, de $51 \%$ para $73 \%$; e nas regiões Nordeste e Norte, de $32 \%$ e $28 \%$ para $55 \%$ e $74 \%$, respectivamente. No estado de São Paulo a variação nos anos 90 e início dos anos 2000 foi de $80 \%$ para 84\% (Andrade, 2004).

FIGURA 2

Participação das matrículas entre instituições públicas e privadas

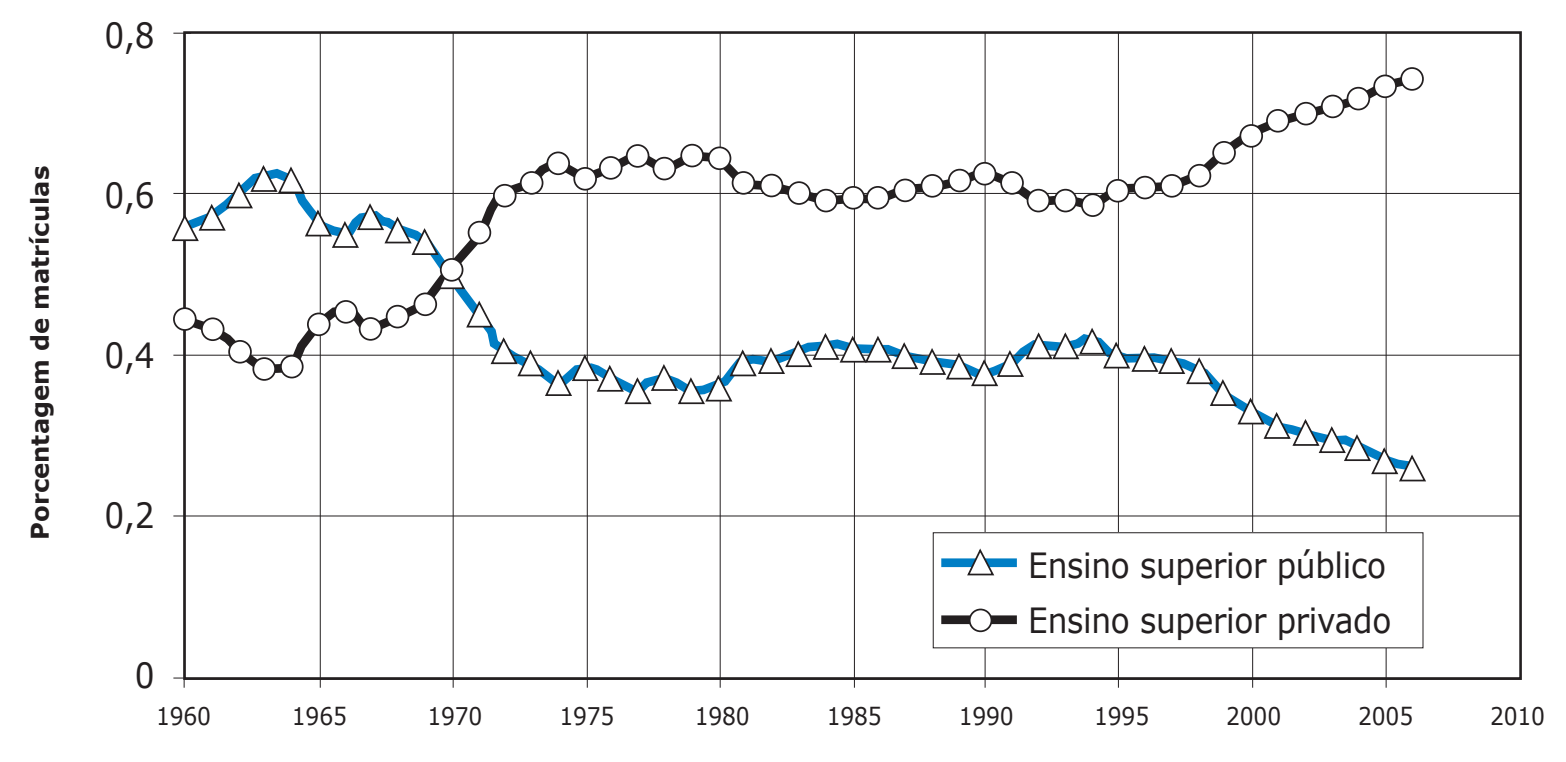

3 Grático extraído de Carvalho 2002. Atualizado para 1985 a 2006, pelos autores deste artigo, a partir dos dados da Sinopse do Ensino Superior, 2002, Inep/MEC.
Nesse período prossegue o movimento de transformação interna das instituições. Transformam-se de instituições isoladas privadas em universidades, ao mesmo tempo em que crescem em número de matrículas. Ademais a multiplicação dos campi e a diversificação dos cursos empreendida por parte das universidades recentemente criadas são tendências características (Fapesp, 2001).

Esses fenômenos ocorreram primeiramente e de forma mais intensa no estado de São Paulo e depois nos demais estados da região. A seguir, a mesma tendência de crescimento do setor privado ocorre
Os significativos movimentos de desconcentração e interiorização relacionam-se, por um lado, à melhoria do perfil de escolaridade e também à dinâmica de desenvolvimento socioeconômico do país que se caracteriza-se pela crescente desconcentração e diversificação das cadeias produtivas, expansão do agronegócio e do setor de serviços e pelo crescimento das cidades médias, acompanhados do aumento dos requisitos educacionais exigidos pelo mercado de trabalho e, por outro, da procura do setor privado de ensino superior por novos mercados para contínua expansão. 
O quadro dinâmico de transformações do ensino a partir dos anos 90, caracterizado pela descentralização geográfica no sentido da desconcentração de matrículas de São Paulo para os demais estados da Região Sudeste e desta para as outras regiões do país, complementa-se também pelo fenômeno da interiorização. Tal fenômeno pode ser observado através da maior participação relativa de matrículas nas cidades interioranas brasileiras em relação às capitais dos estados.

Paralelamente a esses movimentos verifica-se ainda o incremento proporcional de matrículas no período noturno nas instituições já estabelecidas. Temos hoje $61 \%$ do total das matrículas oferecidas em cursos noturnos. Quando se observa a oferta de matrículas noturnas, exclusivamente na rede pública nacional, chama atenção seu baixo percentual. As instituições federais, apesar de terem aumentado essa proporção nos últimos anos, respondem, em 2006, por apenas $25 \%$ dos alunos matriculados no turno noturno ${ }^{4}$, e a rede estadual brasileira faz o movimento inverso das demais redes. Oferecia $46 \%$ das matrículas noturnas em 1998 e reduz para $41 \%$ em 2006.

Nas universidades estaduais paulistas, nota-se o esforço em atender ao dispositivo constitucional que torna obrigatória a oferta de um terço de suas vagas no período noturno. De fato, o percentual de matrículas em seus cursos noturnos cresceu de $24 \%$, em 1998, para 35\%, em 2005. No entanto, ainda há uma série de cursos oferecidos por essas instituições, como medicina, odontologia, entre outros, que, devido à carga horária e à dedicação exclusiva, exigem do alunado o estudo em tempo integral. Esse fato é um limitante à expansão de vagas no período noturno ${ }^{5}$.

Outro fator importante de diferenciação entre o ensino superior público e o privado é o conjunto das áreas de conhecimento nas quais os cursos são oferecidos. As instituições privadas oferecem principalmente cursos nas áreas de humanas ou de formação geral. Dessa forma, devido à preponderância quantitativa do setor privado, o resultado é que mais de $60 \%$ dos alunos no Brasil se formam em apenas quatro áreas: ciências sociais/negócios/direito e educação. A seguir, a área de saúde e bem-estar social apresenta um percentual de formados bem inferior, em torno de $13 \%$. As áreas de ciências/matemática/computação e engenharia vêm em $3^{\circ}$ lugar, apresentando percentuais inferiores a $10 \%$ dos concluintes (Censo do Ensino Superior).

As estaduais paulistas e a rede federal em seu conjunto ${ }^{6}$ apresentam uma oferta mais equilibrada entre as áreas de conhecimento. O restante da rede estadual, longe de apresentar esse equilíbrio, concentra mais da metade de seus formandos em apenas uma área (54,5\% em educação), percentual ainda mais alto do que o apresentado pelas particulares.

Levando-se em consideração que a demanda potencial pelo ensino superior é composta, em parte, pelos concluintes do ensino médio, podemos constatar que a oferta de vagas noturnas na rede pública é ainda insuficiente, em face da predominância do alunado que conclui o ensino médio público no período noturno. O contingente de concluintes no setor público é composto por $84 \%$ do total dos concluintes, e desses $57 \%$ cursaram o período noturno. O ensino médio privado, por sua vez, é responsável por apenas $16 \%$ dos concluintes, sendo apenas $1 \%$ no período noturno (dados do Censo Escolar ME/Inep, 2006).

Grande parte dessa demanda potencial tem sido atendida pelo ensino superior privado. Esse setor foi responsável, em 2006, por $84 \%$ do total das matrículas oferecidas no período noturno. $\mathrm{Na}$ rede privada predomina também a oferta de cursos que não exigem dedicação exclusiva - período integral - como vimos acima.

Em resumo, a distribuição de matrículas noturnas na graduação, de modo geral, tem um comportamento similar àquela do alunado concluinte do ensino médio nesse turno. Porém, segundo a dependência administrativa, a disparidade entre as matrículas de graduação e as conclusões no ensino médio noturno revela a inadequação do fluxo escolar entre os dois níveis de ensino, podendo representar um dos gargalos à expansão do acesso ao ensino superior.
4 Vale salientar que esse indicador é uma média entre instituiç̧ões muito heterogêneas. Algumas oferecem mais de $40 \%$ de suas matrículas em cursos noturnos, enquanto outras menos de 10\%. A título de exemplificação, no primeiro caso, cita-se a Universidade do Rio de Janeiro (Unirio), a Universidade Federal do Mato Grosso do Sul e a Universidade Federal do Acre.

$5 \mathrm{Na}$ Universidade Estadual de Campinas (Unicamp) para todas as modalidades do curso de engenharia, carreira típica de dedicação em período integral, são ofertadas vagas no noturno.

6 É preciso, no entanto, levar em conta a heterogeneidade de porte e qualidade das instituições federais. Por exemplo, enquanto as federais do Rio de Janeiro (UFRJ), Minas Gerais (UFMG), Rio Grande do Sul (UFRGS), Brasilia (UnB) e Santa Catarina (UFSC) apresentam uma proporção de mais de $50 \%$ de professores doutores, outras federais, tais como as do Amapá, Amazonas, Rondônia, Acree Roraima possuem menos de 10\% de professores doutores Dados e Indicadores das Instituições Federais de Ensino Superior, 2000, Brasília, DF, novembro de 2002) 


\section{CARACTERISIICAS}

\section{DA DEMANDA/EVOLUÇÃOO DO ACESSO À EDUCAÇÃO NO BRASIL DE 1995 A 2006}

O contingente populacional considerado como demanda adequada para o ensino superior é aquele composto pela população com idade entre 18 e 24 anos. Esse é o indicador utilizado pelas agências internacionais. Porém, no Brasil, essa faixa etária representa apenas pouco mais da metade daqueles que freqüientam o ensino superior. Devido ao atraso escolar, à entrada precoce no mercado de trabalho, às dificuldades em cumprir com o pagamento das mensalidades, entre outras dificuldades das gerações mais novas, as faixas etárias mais velhas têm grande representação entre aqueles que freqüentam o ensino superior, pois sofrem a pressão do mercado de trabalho no sentido de obter maior escolaridade.

Apesar da intensa expansão da oferta de vagas ocorrida no Brasil, nos últimos anos, o percentual de jovens na faixa etária de 18 a 24 anos freqüentando o ensino superior, em 2006, é de apenas 16\% (Inep/MEC, 2006). No entanto, para analisar as possibilidades de expansão do acesso a esse segmento do ensino, é preciso levar em conta não apenas a idade, mas também a qualificação formal necessária para o acesso. Nesse sentido, é necessário examinar tanto o nível de escolaridade alcançado pelos jovens como a evolução obtida nos últimos anos.

\section{0 acesso ao ensino superior dos jovens de 18 a 24 anos}

Os dados apresentados a seguir evidenciam que o atraso escolar é uma das restrições ao acesso de jovens brasileiros ao ensino superior: $27 \%$ dos jovens de 18 a 24 anos não haviam sequer completado o ensino fundamental e outros $27 \%$, apesar de terem completado o ensino fundamental, não ingressaram no ensino médio, ou ingressaram, mas não o concluíram. Esses contingentes somados representam mais da metade dos jovens (54\%) sem a qualificação formal para ingressarem noensino superior. Em números absolutos são mais de 12 milhões de jovens. Temos outros $30 \%$ que concluíramo ensino médio, mas não tiveram acesso ao ensino superior. E, finalmente, apenas $16 \%$ que tiveram acesso ao ensino superior, segundo os dados da PNAD, 2006. Em números absolutos representam $7 \mathrm{mi}$ lhões de jovens com escolaridade de nível

TABELA 2

Taxa da população com idade entre 18 e 24 anos, segundo o nível de escolaridade. Brasil - 2006

\begin{tabular}{|l|c|}
\hline \multicolumn{1}{|c|}{ Situação escolar } & $\%$ \\
\hline Não concluiu o ensino fundamental & $27 \%$ \\
\hline Concluiu apenas o ensino fundamental & $27 \%$ \\
\hline Concluiu o ensino médio & $30 \%$ \\
\hline Teve acesso ao ensino superior & $16 \%$ \\
\hline Total & $100 \%$ \\
\hline
\end{tabular}

Fonte: PNAD/IBGE, 2006. 
TABELA 3

Evolução do acesso à educação em termos de percentuais da população na idade de 18 a 24 anos, segundo o nível de escolaridade. Brasil - 1995 e 2006

\begin{tabular}{|l|c|c|c|c|c|}
\hline \multirow{2}{*}{} & \multicolumn{2}{|c|}{1995} & \multicolumn{2}{c|}{2006} & Var. \\
\cline { 2 - 6 } & \multicolumn{1}{|c|}{ abs. } & \multicolumn{1}{c|}{$\%$} & abs. & $\%$ & $\%$ \\
\hline Não concluiu o ensino fundamental & 10.543 .903 & $58 \%$ & 6.462 .254 & $27 \%$ & $-39 \%$ \\
\hline Concluiu apenas o ensino fundamental & 4.198 .864 & $23 \%$ & 6.408 .301 & $27 \%$ & $53 \%$ \\
\hline $\begin{array}{l}\text { Concluiu o ensino médio, mas não teve } \\
\text { acesso ao ensino superior }\end{array}$ & 2.192 .191 & $12 \%$ & 7.206 .627 & $30 \%$ & $229 \%$ \\
\hline Teve acesso ao ensino superior & 1.320 .357 & $7 \%$ & 3.691 .272 & $16 \%$ & $180 \%$ \\
\hline Total & 18.255 .315 & $100 \%$ & 23.768 .454 & $100 \%$ & \\
\hline
\end{tabular}

Fonte: PNAD/IBGE, 1995 e 2006.

médio e outros 3,7 milhões que tiveram acesso ao ensino superior.

A seguir comentamos as variações observadas entre 1995 e 2006.

De 1995 a 2006 o percentual de jovens que não concluíram o ensino fundamental reduziu-se praticamente pela metade, de $58 \%$ para $27 \%$, uma queda expressiva. Mesmo assim, permanece o significativo índice de aproximadamente $30 \%$ de jovens sem concluir o ensino fundamental.

O percentual dos jovens que, apesar de ter concluído o ensino fundamental, não prosseguiram os estudos no ensino médio manteve-se praticamente inalterado durante o período em foco, variando de $23 \%$ para $27 \%$.

$\mathrm{O}$ percentual daqueles que atingiram o ensino médio como o mais alto grau de escolaridade apresentou expressivo crescimento de $229 \%$, mas sobre uma base pequena, pois passou de $12 \%$ para $30 \%$. A atual proporção de $30 \%$ de concluintes do ensino médio ainda representa um percentual muito distante daquele encontrado em países mais desenvolvidos que beira à universalização do acesso a esse nível de ensino.

Finalmente, a parcela daqueles que tiveram acesso ao ensino superior cresceu apenas de $7 \%$ para $16 \%$ durante os dez anos analisados (Tabela 3).
As séries históricas da evolução do acesso à educação dos jovens de 18 a 24 anos no Brasil são mostradas na Figura 3.

\section{Evolução do acesso segundo a cor da pele autodeclarada}

Como vimos, grande parcela da população jovem não possui os requisitos educacionais formais necessários para o acesso ao nível superior: mais de $50 \%$ sequer atingiram o nível médio e, desses, a metade não atingiu nem ao menos a conclusão do ensino fundamental. É muito reduzida a parcela que chegou a ingressar em cursos de nível superior. Além dessa constatação, podemos verificar que os níveis de escolaridade se diferenciam entre os jovens que se autodeclararam pertencentes à população branca e não-branca. A população nãobranca apresenta níveis inferiores de escolaridade em relação à população branca. As maiores diferenças podem ser observadas entre aqueles que não concluíram sequer o ensino fundamental e entre os que tiveram acesso ao ensino superior. No primeiro caso, temos $18 \%$ de brancos e $36 \%$ de não-brancos. No segundo caso, são $24 \%$ de brancos 
FIGURA 3

Evolução do acesso à educação no Brasil para jovens com idade entre 18 e 24 anos
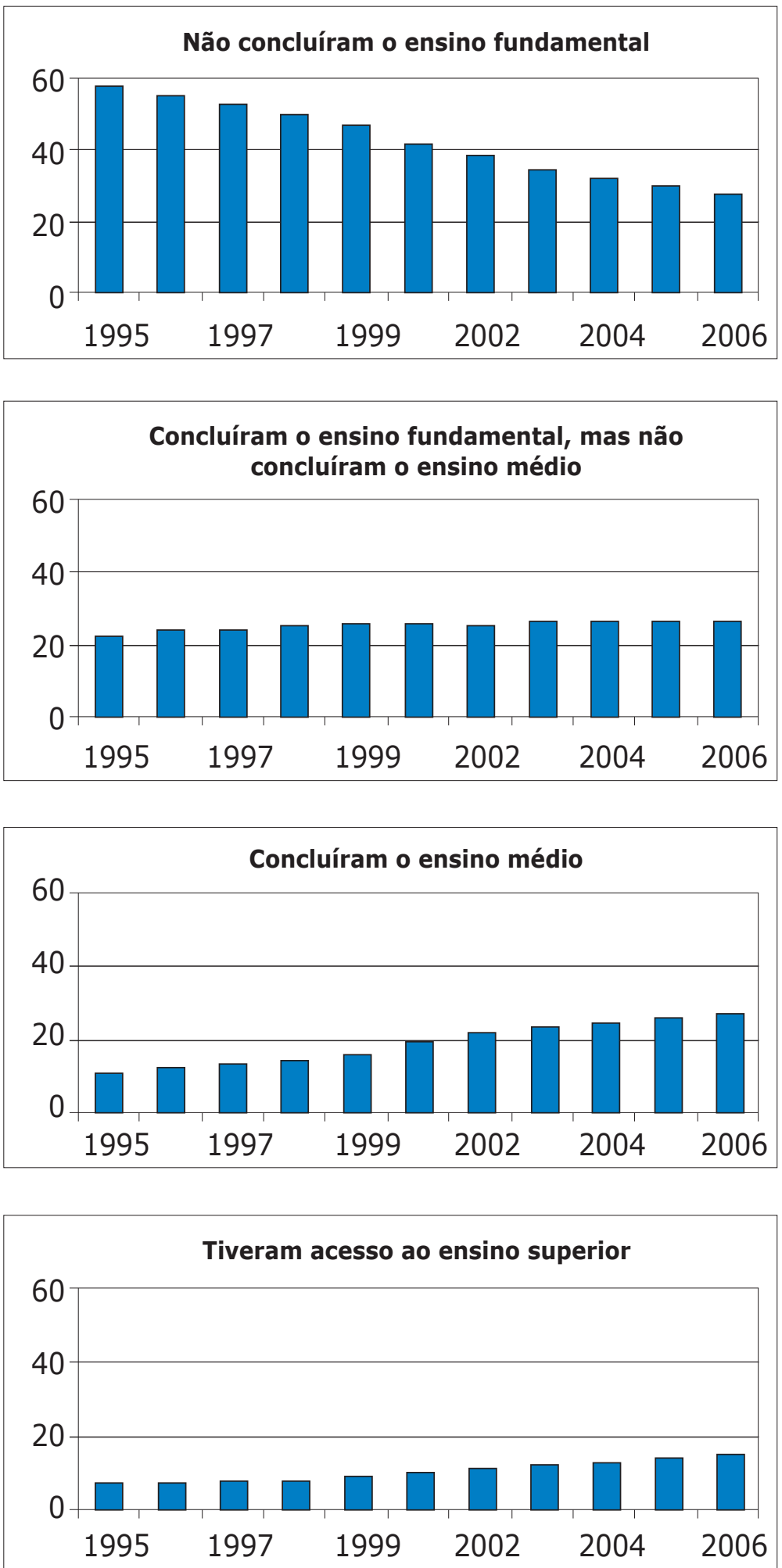

Fonte: PNAD/IBGE 
TABELA 4

Acesso à educação segundo a cor autodeclarada

\begin{tabular}{|l|r|c|r|}
\hline & Brancos & Não-brancos & Todos \\
\hline Não concluiu o ensino fundamental & $18 \%$ & $35 \%$ & $27 \%$ \\
\hline Concluiu apenas o ensino fundamental & $23 \%$ & $29 \%$ & $26 \%$ \\
\hline Concluiu o ensino médio & $33 \%$ & $27 \%$ & $30 \%$ \\
\hline Teve acesso ao ensino superior & $24 \%$ & $7 \%$ & $15 \%$ \\
\hline Total & $100 \%$ & $100 \%$ & $100 \%$ \\
\hline
\end{tabular}

Fonte: PNAD 2006

e apenas 7\% de não-brancos.

As diferenças são menos acentuadas entre aqueles que concluíram, ao menos, o ensino fundamental e aqueles que lograram atingir a conclusão do ensino médio, como podemos observar na Tabela 4 .

A Tabela 5 mostra que o nível de escolaridade daqueles que se autodeclararam brancos progrediu de forma mais expressiva no sentido de atingir a conclusão do ensino médio e de ter acesso ao ensino superior. Enquanto a maioria dos nãobrancos progrediu no sentido de atingir a conclusão do ensino fundamental e do ensino médio ${ }^{7}$. O contingente de jovens que lograram atingir a conclusão do ensino médio passa a ser muito semelhante entre brancos e não-brancos (1.657.602 e 1.505.557 respectivamente). Ou seja, a grande diferença da evolução no período analisado localiza-se na quantidade de jovens autodeclarados como brancos que atingiram oensino superior (1.657.602 pessoas) enquanto quantidade semelhante de não-brancos atingiu a conclusão do ensino fundamental (2.006.375 pessoas).

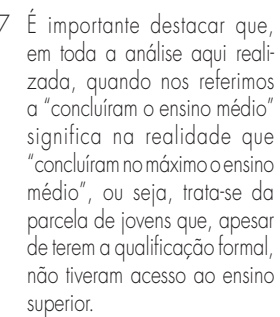
superior.

\section{TABELA 5}

Número de jovens com idade de 18 a 24 anos e variação entre 1995 e 2006 segundo as categorias de acesso à educação analisadas neste trabalho

\begin{tabular}{|l|c|c|c|}
\hline \multicolumn{3}{|c|}{ Brancos } \\
\hline & 1995 & 2006 & Variação \\
\hline Não concluiu o ensino fundamental & 4.636 .355 & 2.060 .263 & -2.576 .092 \\
\hline Concluiu apenas o ensino fundamental & 2.482 .641 & 2.685 .703 & 203.062 \\
\hline $\begin{array}{l}\text { Concluiu o ensino médio, mas não teve } \\
\text { acesso ao ensino superior }\end{array}$ & 1.481 .901 & 3.815 .924 & 2.334 .023 \\
\hline Teve acesso ao ensino superior & 1.112 .065 & 2.769 .667 & 1.657 .602 \\
\hline & 5.907 .548 & 4.401 .991 & -1.505 .557 \\
\hline Não concluiu o ensino fundamental & 1.716 .223 & 3.722 .598 & 2.006 .375 \\
\hline Concluiu apenas o ensino fundamental & 710.290 & 3.390 .703 & 2.680 .413 \\
\hline $\begin{array}{l}\text { Concluiu o ensino médio, mas não teve } \\
\text { acesso ao ensino superior }\end{array}$ & 208.292 & 921.605 & 713.313 \\
\hline Teve acesso ao ensino superior & & & \\
\hline
\end{tabular}




\section{Evolução do acesso segundo a renda familiar per capita}

O acesso às categorias educacionais descritas na Tabela 1 em 1995 e em 2006 bem como a variação em números absolutos são mostrados na Tabela 6 para o $1^{\circ}$ e para o 5o quintis da distribuição de renda per capita familiar.

De 1995 para 2006, no 1 quintil, 571 mil jovens a mais passaram a concluir o ensino fundamental, o que pode ser consideradoum resultado auspicioso. Entretanto, no acesso ao ensino superior o progresso foi extremamente limitado: apenas $21 \mathrm{mil}$ jovens a mais passaram a freqüentar o ensino superior.

Ao mesmo tempo, 369 mil jovens do 1 음 quintil concluíram o ensino médio, o que indica uma real barreira no acesso ao en- sino superior para jovens mais pobres.

De outro lado, e em forte contraste, no mesmo período para o 5ㅇ quintil se observa que ao lado de um aumento de 1,2 milhão de jovens concluindo o ensino médio sem ir ao ensino superior se associa a um aumento de 1,7 milhão de jovens chegando ao ensino superior indicando que mais da metade dos novos concluintes do ensino médio nessa faixa de renda obtém acesso ao ensino superior.

O contraste entre o acesso ao ensino superior para os jovens do $5^{\circ}$ quintil em relação aos do $1^{\circ}$ quintil merece ser destacado: no 1 o quintil, $1 \%$ dos jovens, em 2006, chegam ao ensino superior. Para os jovens do $5^{\circ}$ quintil este percentual é $43 \%$, fazendo com que a chance de um jovem do $5^{\circ}$ quintil chegue ao ensino superior seja 43 vezes maior do que para um jovem do $1^{\circ}$ quintil. Voltaremos a esse ponto nas Conclusões.

\section{TABELA 6}

\section{Categorias de acesso à educação em 1995, em 2006 e variação absoluta}

\begin{tabular}{|c|c|c|c|}
\hline & 1995 & 2006 & Variação \\
\hline \multicolumn{4}{|l|}{ 10 quintil } \\
\hline Não concluiu o ensino fundamental & 2.495 .305 & 1.923 .824 & -571.481 \\
\hline Concluiu apenas o ensino fundamental & 299.948 & 918.218 & 618.270 \\
\hline $\begin{array}{l}\text { Concluiu o ensino médio, mas não teve } \\
\text { acesso ao ensino superior }\end{array}$ & 62.705 & 431.655 & 368.950 \\
\hline Teve acesso ao ensino superior & 14.249 & 35.429 & 21.180 \\
\hline Total & 2.872 .207 & 3.309 .126 & 436.919 \\
\hline \multicolumn{4}{|l|}{ 5o quintil } \\
\hline Não concluiu o ensino fundamental & 1.131 .347 & 368.766 & -762.581 \\
\hline Concluiu apenas o ensino fundamental & 1.373 .089 & 1.037 .328 & -335.761 \\
\hline $\begin{array}{l}\text { Concluiu o ensino médio, mas não teve } \\
\text { acesso ao ensino superior }\end{array}$ & 1.048 .182 & 2.212 .910 & 1.164 .728 \\
\hline Teve acesso ao ensino superior & 1.071 .186 & 2.764 .753 & 1.693 .567 \\
\hline Total & 4.623 .804 & 6.383 .757 & 1.759 .953 \\
\hline
\end{tabular}


TABELA 7

Distribuição percentual do acesso ao ensino superior público e ao ensino superior privado, segundo os quintis de renda para jovens com idade de 18 a 24 anos

\begin{tabular}{|l|c|c|c|c|c|c|}
\hline & $\mathbf{1 0}$ quintil & 20 quintil & 30 quintil & 40 quintil & 5ㅇ quintil & Total \\
\hline $\begin{array}{l}\text { Ensino superior } \\
\text { público }\end{array}$ & 0,95 & 4,00 & 9,33 & 17,83 & 67,88 & 792.994 \\
\hline $\begin{array}{l}\text { Ensino superior } \\
\text { privado }\end{array}$ & 0,84 & 1,29 & 5,35 & 15,35 & 77,17 & 2.166 .389 \\
\hline Total & 0,87 & 2,02 & 6,42 & 16,01 & 74,69 & 2.959 .383 \\
\hline
\end{tabular}

Fonte: PNAD 2006

\section{Acesso ao ensino superior público e privado}

A Tabela 7 mostra a distribuição das matrículas no ensino superior público e privado segundo a condição de renda da população, classificada em quintis. Do total de 2.959.383 de jovens com idade entre 18 e 24 anos que cursavam o ensino superior em 2006, 27\% encontravam-se no setor privado e $73 \%$ no ensino superior público. Podemos observar que os percentuais de participação no ensino superior crescem conforme cresce a renda e essa tendência ocorre tanto no setor privado como no setor público.

No decorrer dos últimos quatro anos não houve alterações significativas na distribuição de vagas do ensino superior. Em todos os quintis de renda as proporções de acesso se mantêm praticamente sem alterações entre os anos de 2003 e 2006 (Tabela 7).

Os jovens pertencentes ao quintil mais alto da renda respondem por $75 \%$ do total das matrículas, havendo uma tendência decrescente em direção aos quintis de menor renda.

Como vimos, a maioria das vagas no ensino superior é oferecida pelo setor privado, havendo mais de 2 milhões de matriculados nesse setor, segundo os dados da PNAD/2006. Em comparação, o setor público responde por $37 \%$ das matrículas, sendo, em números absolutos, menos de 800 mil alunos.

No ensino superior público o número de matrículas de jovens dos quintis de menor renda apresenta-se superior ao que se observa no ensino superior privado. Para jovens do $1^{\circ}$ e $2^{\circ}$ quintis a presença no ensino superior público é mais que o dobro da que se verifica no ensino superior privado. Inversamente, nos quintis mais altos a presença dos jovens é maior no ensino superior privado do que no ensino superior público.

Em resumo, a presença da parcela mais rica da população no ensino superior é muito maior do que dos outros estratos da renda, e eles ocupam, proporcionalmente, mais vagas no setor privado do que no setor público. Essa constatação contraria o senso comum, amplamente divulgado pela imprensa, de que "os ricos estudam nas universidades públicas e gratuitas, enquanto os pobres têm acesso quase que exclusivamente ao ensino superior privado". Ou seja, os pobres têm tido pouco acesso ao ensino superior no Brasil, mas aqueles poucos que aí chegam ocupam proporcionalmente mais vagas no ensino superior público do que no ensino superior 
privado. Esse fenômeno reforça a necessidade da ampliação das vagas públicas e gratuitas e em cursos noturnos no sistema do ensino superior nacional.

Muitos pesquisadores têm se dedicado à analise da correlação entre cor da pele dos indivíduos e sua evolução no sistema educacional. Entre outros podemos citar: Jaccoud \& Beghin, 2002; Guimarães, 2003; Beltrão, 2003; Beltrão \& Teixeira, 2004; Oliveira 2005: Soares et al. 2005. Outros pesquisadores demons tram que a introdução de determinadas variáveis, tais como a distribuição regional da população, os anos de estudo do chefe do domicílio, chefia feminina, o tamanho das familias e especialmente a renda não elimina o efeito da cor nas diferenças de acesso da crianças ao ensino regular, mas causa uma redução bastante considerável. Ver Barros, 2001; Henriques, 2001; Hasenbalg \& Silva, 1999, entre outros. Schwartzman (1999), por sua vez, associou a condição de raça/cor e anos de estudo dos indivíduos segundo o rendimento médio mensal. Conclui que "é claramente a educação e não a cor, raça ou origem o grande fator de desigualdade na sociedade brasileira", porque a diferença de rendimentos, por ele encontrada, entre os mais educados e os menos educados éde 9,9 vezes. Diferença muito maior do que a encontrada entre raça e cor (2,2 vezes) entre os que ganham mais amarelos) e os que ganham menos (pardos) com o mesmo nivel de escolaridade.

\section{CONCLUSÕES}

Em conclusão, pode-se afirmar que, mesmo com os importantes ganhos em termos de acesso à educação verificados no Brasil para jovens de idade entre $18 \mathrm{e}$ 24 anos, ainda há um longo caminho a ser percorrido.

Atualmente há pelo menos duas importantes restrições na oferta de oportunidades de acesso ao ensino superior. Primeiro, existe uma baixa taxa de sucesso, especialmente nos quintis de menor renda, na conclusão do ensino médio e, até mesmo, do ensino fundamental. Pelo menos 54\% dos jovens na faixa de idade estudada não concluemo ensino médio, sendo que, destes, $27 \%$ não concluem nem mesmo o ensino fundamental.

A segunda importante restrição é o pequeno número de vagas em cursos no ensino superior público. Esse fato afeta especialmente os jovens mais pobres, visto que nos quintis de menor renda a presença relativa no ensino superior público é duas vezes maior do que no privado.
TABELA 8

\section{Resumo dos percentuais de jovens que chegam ao ensino superior em função da renda familiar per capita e da cor autodeclarada}

\begin{tabular}{|l|c|c|c|}
\hline & 10 quintil & 5o quintil & Var. \\
\hline Branco & $2,8 \%$ & $49,1 \%$ & 17,9 \\
\hline Não-branco & $0,5 \%$ & $29,6 \%$ & 64,2 \\
\hline Var. & 6,0 & 1,7 & \\
\hline
\end{tabular}

Fonte: PNAD 2006
Pelo lado do acesso, um importante resultado dos dados mostrados é que se pode, a partir deles, aferir o papel da renda e da cor autodeclarada em determinar a intensidade de cada uma dessas duas restrições ao acesso ao ensino superior.

Há um efeito limitado da cor autodeclarada: para jovens do 1ำ quintil de renda a cor branca aumenta por um fator 6 a chance de acesso ao ensino superior. No $5^{\circ}$ quintil a cor branca aumenta por um fator 2 as chances.

A dimensão renda familiar per capita causa diferenças bem mais intensas: para os jovens com cor autodeclarada branca estar no 5우 quintil aumenta as chances de acesso ao ensino superior 18 vezes. Para aqueles com cor autodeclarada não-branca as chances aumentam de forma impressionante: 64 vezes.

Pode-se supor que os efeitos observados em relação aos dados da Tabela 8 seriam mitigados ao se reduzir a diferença de renda das classes comparadas, mas isso não é o que se observa. Na Tabela 9 mostra-se os percentuais de acesso ao ensino superior considerando-se na classe de menor renda a soma do $1^{\circ}$ e $2^{\circ}$ quintis e na de maior renda o $4^{\circ}$ e $5^{\circ}$ quintis.

O efeito da cor autodeclarada torna-se menos evidente para a classe de menor renda: a diferença de percentuais de acesso varia por um fator $3 \mathrm{em}$ vez de 6 quando a comparação usa apenas o $1^{\circ}$ quintil. Para a classe de maior renda o fator favorecendo os de cor autodeclarada branca permanece em torno de 2 .

Na dimensão renda familiar per capita a vantagem para a classe de maior renda é 13 entre os autodeclarados brancos e 20 entre os autodeclarados não-brancos, permanecendo o efeito renda bem mais intenso do que o efeito cor autodeclarada.

Em resumo, para todas as categorias de renda nota-se que os não-brancos apresentam piores condições de escolaridade que os brancos, fato já amplamente documentado no Brasil. No entanto, a renda familiar per capita constitui-se um determinante bem mais forte do que a variável cor da pele ${ }^{8}$. 
TABELA 9

Resumo dos percentuais de jovens que chegam ao ensino superior em função da renda familiar per capita, usando a soma de dois quintis, e da cor autodeclarada

\begin{tabular}{|l|c|c|c|}
\hline & $\mathbf{1}^{\circ} \mathbf{e} \mathbf{2}^{\circ}$ quintis & 4 $^{\circ} \mathbf{5}^{\mathbf{0}}$ quintis & Var. \\
\hline Branco & $2,8 \%$ & $36,5 \%$ & 13,0 \\
\hline Não-branco & $0,9 \%$ & $18,0 \%$ & 19,6 \\
\hline Var. & 3,0 & 2,0 & \\
\hline
\end{tabular}

Fonte: PNAD 2006

\section{BIBLIOGRAFIA}

ANDRADE, Cibele Yahn. "Ensino Superior: Expansão e Desafios", in ComCiência, Revista Eletrônica de Jornalismo Científico, número 54, maio de 2004.

BARROS, Ricardo P. de. et al. "Determinantes do Desempenho Educacional no Brasil", in Texto para Discussão - Ipea. № 834, Rio de Janeiro, 2001.

BeltRÃ0, Kaizô I. “Acesso à Educação: Diferenciais entre os Sexos”, in Texto para Discussão - Ipea. no 879, Rio de Janeiro, 2002.

. "Alfabetização por Sexo e Raça no Brasil: um Modelo Linear Generalizado para Explicar a Evolução no Período 1940-2000", in Texto para Discussão - Ipea. no 1.003, Rio de Janeiro, 2003.

; TEIXEIRA, Moema de P. "0 Vermelho e o Negro: Raça e Gênero na Universidade Brasileira - uma

Análise da Seletividade das Carreiras a Partir dos Censos Demográficos de 1960 a 2000", in Texto para Discussão - Ipea. no 1.052, Rio de Janeiro, 2004.

Camarano, Ana A. et al. "Caminhos para a Vida Adulta: as Múltiplas Trajetórias dos Jovens Brasileiros", in Texto para Discussão - Ipea. no 1.038, Rio de Janeiro, 2004.

CARVALHO, Cristina Helena Almeida de. Reforma Universitária e os Mecanismos de Incentivo à Expansão do Ensino Superior Privado no Brasil (1964-1984). Dissertação de mestrado. Campinas - Instituto de Economia da Unicamp, 2002. CASTRO, Maria Helena Guimarães. "Avaliação do Sistema Educacional Brasileiro: Tendências e Perspectivas". Trabalho apresentado ao Seminário Especial Um Modelo de Educação para o Século XXI. Rio de Janeiro, 1998.

. "Enfoque e Perspectivas da Avaliação para o Ensino de Graduação". Trabalho apresentado ao Seminário Novos Rumos da Graduação: Políticas de Ensino e de Avaliação. Recife, XV Fórum Nacional de Pró-Reitores de Graduação das Universidades Brasileiras, mai./2002.

"Estratégia de Adaptação do Sistema de Educação para Atender à Economia do Conhecimento".

Trabalho apresentado ao XIV Fórum Nacional do Instituto Nacional de Altos Estudos, in Estudos e Pesquisas, o 24, Rio de Janeiro, mai./2002.

. "Estado, Mercado e Desigualdades Sociais no Ensino Superior", in Lauro Morthy (org.). Universidade em Questão. Brasília, Editora UnB, 2003.

CORBUCCI, Paulo. "0 Ensino Superior Brasileiro na Década de 90", in Políticas Sociais. Acompanhamento e Análise, n.

2, Ipea, fev./2001. 
CORSEUIL, Carlos H.; SANTOS, Daniel D.; FOGUEL, Miguel N. “Decisões Críticas em Idades Críticas: a Escolha dos Jovens entre Estudo e Trabalho no Brasil e em Outros Países da América Latina", in Texto para Discussão - Ipea. no -797 , Rio de Janeiro, 2001.

CUNHA, Luiz Antonio. "Critério de Avaliação e Credenciamento do Ensino Superior: Brasil e Argentina", in Jacques Velloso (org.). 0 Ensino Superior e o Mercosul. Brasília, Garamond/Unesco, 1998. "O Ensino Superior no Octênio FHC", in Educação e Sociedade, v. 24, n. 82, abr./2003.

DURHAM, Eunice R. Uma Política para o Ensino Superior Brasileiro: Diagnóstico e Proposta. São Paulo, Nupes, 1998 (documento de Trabalho Nupes 1/98 - Núcleo de Pesquisa sobre Ensino Superior da USP).

FAPESP. Indicadores de Ciência e Tecnologia e Inovação em São Paulo - Capítulo 3: Ensino Superior: Perfil da Graduação e da Pós-graduação. Fapesp, São Paulo, 2004.

FERNANDES, Danielle C. Estratificação Educacional, Origem Socioeconômica e Raça no Brasil: as Barreiras da Cor (Concurso de Monografia - Prêmio Ipea 40 anos - Ipea-Caixa, 2004 - Tema "A Superação das Desigualdades Sociais no Brasil"). Digitado.

FERRARO, Alceu R.; MACHADO, Nadie C. F. "Da Universalização do Acesso à Escola no Brasil”, in Educação \& Sociedade, ano 23, no 79, 2002.

GUIMARÃES, Antonio S. A. "Acesso de Negros às Universidades Públicas", in Cadernos de Pesquisas, nº 118, 2003.

HENRIQUES, Ricardo. “Desigualdade Racial no Brasil: Evolução das Condições de Vida na Década de 90", in Texto para Discussão - Ipea. no 807, Rio de Janeiro, 2001.

JACCOUD, Luciana; BEGHIN, Nathalie. Desigualdades Raciais no Brasil: um Balanço da Intervenção Governamental. Brasilia, Ipea, 2002.

OLIVEIRA, Fátima. "Ser Negro no Brasil: Alcances e Limites", in Estudos Avançados, v. 18, no 50, 2005.

OSORIO, Rafael G. "A Mobilidade Social dos Negros Brasileiros", in Texto para Discussão - Ipea. no 1.033, Rio de Janeiro, 2004.

ROCHA, Sônia. Pobreza no Brasil: do que se Trata. Rio de Janeiro, 2003.

SAMPAIO, Helena; LIMONGI, Fernando; TORRES, Haroldo. Eqüidade e Heterogeneidade no Ensino Superior Brasileiro. Brasília, Instituto Nacional de Estudos e Pesquisas Educacionais, 2000.

SCHWARTZMAN, Simon. "Fora de Foco: Diversidade e Identidades Étnicas no Brasil”, in Novos Estudos Cebrap, n. 55, 1999, pp. 83-96.

SOARES, José F.; ALVES, Teresa G. “Desigualdades Raciais no Sistema Brasileiro de Educação Básica, in Educ. Pesqui., v. 29, n. 1, São Paulo, 2003. Disponível em: <http://www.scielo.br/scielo.php?pid=S1517-97022003001 00011 \&script=sci_arttex\&tlng=pt>. Acesso em 2 de maio 2005.

SOARES, Sergei; CARVALHO, Luiza; KIPNIS, Bernardo. "Os Jovens de 18 a 25 anos: Retrato de uma Dívida da Política Educacional", in Texto para Discussão - Ipea. no 954, Rio de Janeiro, 2003.

ZUCHI, Juliana. Desigualdade de Renda no Brasil em 2001: a Influência da Cor e da Educação (Concurso de Monografias - Prêmio Ipea 40 anos - Ipea-Caixa, 2004 - Tema "A Superação das Desigualdades no Brasil"). Digitado. 